\title{
Expert Assessment Method in Socio-Economic Research and Scales Transformations
}

\author{
Valentyna Lukianova* \\ Department of Economy of Enterprise \\ and Entrepreneurship \\ Khmelnytskyi National University \\ Khmelnytskyi, Ukraine \\ lukianivww[at]ua.fm
}

\author{
Yuliya Shutyak \\ Independent Researcher \\ Brussels, Belgium \\ https://orcid.org/0000-0001-5986-9040
}

\author{
Valentyna Polozova \\ Department of Economy of Enterprise \\ and Entrepreneurship \\ Khmelnytskyi National University \\ Khmelnytskyi, Ukraine \\ val812p[at]gmail.com
}

\begin{abstract}
The article discusses the expert assessment method and its utilization in socio-economic research. It provides an overview of the main steps in application of this method and main difficulties or concerns that may arise on each of these steps. The authors focus on the scales that experts can use and possibilities of transformation of various scales to assure ease of use of such scales by experts as well as by researchers who evaluate and summarise the results of expert assessment. The article suggests several options of scale transformation and points out to the advantages of such approaches. It concludes with discussing some limitations and advantages of the method and suggests several directions for further research.
\end{abstract}

Keywords-method, expert evaluation, scale, research methodology

\section{INTRODUCTION}

Method of expert evaluations emerged long before any clear idea of the research methodology and remains one of the most popular research methods. The explanation of such popularity lays in the advantages of this method: it can be used in a various areas of social life and applied to various problems. Moreover, it can be used under conditions of time and resource limits and lack of necessary information.

One of its comparatively modern variations is the Delphi method. Since its development in the middle of the last century, this method found its application in economics, politics, policy studies, history, ecology, technology, education, and many others areas of social life. More specific examples include but not limited to evaluation of budget allocations, risks estimation, finding consensus on possible causal relations in complex economic and social phenomena, exploring market behaviour, historical events, finding consensus during policy formulation, forecasting financial markets, forecasting in tourism sector, in health leadership etc. [1]-[5].

Along with its popularity, the Delphi method has been actively discussed by scientists who raised several concerns regarding its validity[6]. Such discussions led to multiple improvements aimed at increase in the method's validity. When some research works were focusing of philosophical and conceptual basis of validity by expertise [7], [8], the others paid more attention to the problem of consensus [2], [9], [10], statistical evaluation of individual evaluations, and application of this methods in a particular domain[4], [9].

At the same time, the analysis of procedures of application of the method revealed one specific problem. The
Delphi technique does not have any uniform evaluation scale which can be used in all areas for all research problems. Although the Likert scale remains one of the most popular, its usage as well as usage of the other types of scales is not always justified by researchers. Further, researchers face the problem of transformation and aggregation of evaluation results so that these results can be easily used by decision makers. Finally, the Delphi method is commonly used by policy makers, educators and other professionals who just starting their scientific career or have no connection to science. It is difficult for these people to use and understand complicated mathematical calculations while the situation requires or allows very often utilization of this particular method. These problems are particularly persistent in Ukrainian science.

Taking into account all of the above, we seek to develop a solution to the problem of scale transformation which can be used by experienced scientists as well as less experienced researchers and other professionals without scientific background.

\section{General ProcedURE}

Expert judgment is a logical statement and conclusions of specialists regarding a particular economic process or phenomenon (object of study). The general procedure of the Delphi method includes analysis of quantitative and qualitative factors by a team of experts. For each individual event or research object (socio-economic process, phenomenon, enterprise, project, operation, etc.), researcher develops a list of factors (evaluation criteria) that affect activity or performance of the research objects and the rating scale for each of the factors. Often, the analysis of selected factors is carried out within two counterparties (internal and external): state structures and the population; the investor and the manufacturer; the customer and the contractor; the seller and the buyer.

The efficiency of the application and reliability of the analysis of the processes by the method of expert assessments largely depends on the competence and number of experts, the quality of factors (criteria), the accuracy and uniqueness of the wording. These factors often limit the widespread use of this method. In the situation of economic reforms in the country or in cases of dramatic changes in the activity of the enterprise, the reliability of estimates obtained on past trends is quite low. Another feature of expert assessment in such circumstances is their non-specific nature. 
In practice, both individual and group (collective) expert evaluations are used. The main goals of using individual expert assessment are:

- forecasting of events and phenomena in the future;

- analysis and generalization of results submitted by other experts;

- development of action scenarios;

- preparing conclusions on the work of other specialists and organizations (reviews, reviews, expertise).

The advantage of individual examination is the speed of obtaining information for decision making and relatively small costs. The disadvantage is the high level of subjectivity and, as a consequence, the decrease in the reliability of the estimates obtained.

Group examinations are generally less subjective and decisions based on them are more likely to be implemented. When resolving an uncertainty, the group's opinion is more reliable than that of an individual expert. There are the following types of group expert procedures:

- open discussion of the issues raised, followed by open or closed voting;

- open submission of own opinion without discussion and voting;

- closed discussion followed by closed voting or completion of expert questionnaires.

As mentioned above, one of the forms of expert evaluation is the Delphi method. The expert survey procedure includes: conducting several tours; during each round, experts provide their opinions and assess the situation; when processing information received from experts, all estimates are arranged in descending order, the median (value placed in the middle of a row) and quartiles (values are obtained by dividing a series of numbers into four equal by number groups); Experts whose estimates fall into the sub-groups (1st and 4th quarters) are asked to substantiate their opinion and to inform other experts without justifying whom they have been informed.

This procedure allows specialists to change their assessment as needed, to take into account circumstances that they may have accidentally missed or neglected in the first round of the survey.

After the second round estimates are obtained, the median and quartile are determined again. This process continues until the movement towards increasing the coincidence of thoughts becomes insignificant.

Given the conventionality of the expert method, some experts mistrust it, believing that there are no guarantees of the reliability of the estimates obtained. Indeed, it is impossible to accurately estimate the reliability of the results obtained, but the existing methods of determining the reliability are based on the assumption that in the case of coherence of the experts' actions, the reliability of the estimates is guaranteed.
It should also be noted that, together with the error caused by the lack of information about the object under study or the lack of expertise of experts, there may be an error due to the interest of experts in the results of the examination, which will necessarily affect the reliability of the estimates. These shortcomings can be eliminated by properly organizing the expert procedure - from the selection of experts to the processing of their assessments.

The general scheme of expert surveys includes the following main steps:

1) selection of experts and formation of expert groups;

2) forming questions and developing questionnaires;

3) working with experts;

4) formulation of rules for determining final grades based on the assessments of individual experts;

5) analysis and processing of expert assessments.

In the first stage, based on the objectives of the expert survey, determine the structure of the expert group, the number of experts and their personal qualities, i.e. requirements for specialization and qualification of experts, the required number of experts of each specialization, their total number in the group.

When conducting a group survey using special economic and mathematical methods, you can determine the optimal number of experts in the group [11]. With a small group of experts, on the one hand, the sense of conducting a group survey is lost, and on the other, the influence of the individual expert's assessments on the final result increases. With the increase of the expert group, new shortcomings may emerge: a decrease in the impact of the assessments of individual experts; involvement of less qualified experts, complication of group coordination and processing of survey results. In addition, when selecting experts, it is desirable to assess, as far as possible, the level of objectivity of individual members of the group, that is, to identify experts whose potential goals are at odds with the purpose of obtaining objective results.

When forming expert groups and selecting specific respondents when conducting a survey, the results of which are used in scientific research (especially at specific enterprises), the following should be considered:

- the number of experts for each research object should be characterized by minimal redundancy, that is, not only top-management but also mid-level specialists working in the data or related fields should be included in the number of respondents. Involving other employees (less informed) will not so much reduce the subjectivity of assessments as it will distort the result due to incompetence;

- when researching different areas of activity and identifying problematic situations, it is best to form several expert groups with the development of separate questionnaires for each research object.

To provide conditions favorable to the formation of objective opinions by experts, it is advisable to observe the following conditions:

- the independence of experts to form their own judgments about the object of study; 
- convenience of work with the questionnaire (questions are formulated in conventional terms, should exclude any meaningful ambiguity, etc.);

- logical correspondence of questions to the structure of the research object;

- sufficient time for answering the questionnaire, convenient time for evaluation;

- maintaining the anonymity of the answers;

- providing the experts with all the necessary information.

Depending on the nature of the object being investigated and the degree of formalization of the object, the possibilities of attracting the necessary experts may vary, but basically it involves three stages:

1) experts are involved individually in order to: specify the model of the object, its parameters and indicators; clarify the formulation of questions and terminology in the questionnaires; agree on the feasibility of certain forms of submission of expert evaluation tables; clarify the composition of the expert group;

2) the experts are provided with questionnaires with explanatory letter, which describes the purpose of the work, the structure and the order of construction of tables with possible examples (this information can be communicated to the experts and orally). The self-completion of questionnaires should be ensured, in certain cases while maintaining anonymity;

3) work with experts is carried out after obtaining the results of the survey in the process of processing and analysis of the obtained results (experts in the form of consultation, if necessary, receive all the necessary information to clarify the data and their final analysis).

\section{SCALES TRANSFORMATIONS}

Depending on the specifics of the expert survey, the object of study and the method used to process the expert data, the expert assessment may have different scales of measurement: from 0 to 1 (probability of manifestation, or occurrence of a certain type of phenomena); from 0 to 10 ; 0 to 100 , etc.

To simplify the procedure less experienced scientists or professionals who have no connection to science, formulate a scale of expert assessments based on the scale of the desired evaluation results, which often complicates the evaluation procedure of a particular expert due to a partial distortion of information.

It should be noted that in most cases, a specific expert seeks to minimize their time to fill in the questionnaire, so developers of a questionnaire should not only specify and clearly define the criteria, but also use an easy to interpret scale for evaluation.

Therefore, we suggest considering several examples, focusing on the issues raised above.

Example 1. Survey participants (employees of an enterprise) evaluate the existing problems in carrying out a certain type of activity (investment project). The purpose of the assessment is to obtain a probability for each partial problem identified and a group of such problems.

Accordingly, Tables 1, 2 and 3 present variants of possible estimates.

TABLE I. EXPERT ASSESSMENT OF PROBABILITY (OPTION 1)

\begin{tabular}{|c|c|c|}
\hline $\begin{array}{c}\text { Group of } \\
\text { problems }\end{array}$ & Partial problem & Probability \\
\hline \multirow{2}{*}{ 1. Political } & 1.1. Terrorist act & 0,05 \\
\cline { 2 - 3 } & 1.2. & 0,10 \\
\cline { 2 - 3 } & $\ldots$ & 0,15 \\
\hline 2. Technical & $\begin{array}{c}\text { 2.1. Lack of necessary modern } \\
\text { equipment }\end{array}$ & 0,18 \\
\cline { 2 - 3 } & $\ldots$ & 0,15 \\
\hline 3. Economic & 3.1. Inability to get a loan & 0,25 \\
\cline { 2 - 3 } & $\ldots$ & $\mathbf{1 , 0 0}$ \\
\hline Total & & \\
\hline
\end{tabular}

Tables 1 and Table 2 contain estimates on a scale from 0 to 1 , which enables one to obtain the probability immediately after processing the questionnaires without any mathematical transformations (this task was specifically set before the experts). The survey, whose results are presented in Table 2, was conducted in two stages: 1) determining the probability for each group of problems; 2) determining the probability for each partial problem within the group.

TABLE II. EXPERT ASSESSMENT OF PROBABILITY (OPTION 2)

\begin{tabular}{|c|c|c|}
\hline $\begin{array}{l}\text { Group of } \\
\text { problems }\end{array}$ & Partial problem & Probability \\
\hline \multicolumn{3}{|c|}{ Stage 1} \\
\hline \multicolumn{2}{|r|}{ 1. Political } & 0,20 \\
\hline \multicolumn{2}{|r|}{ 2. Technical } & 0,35 \\
\hline \multicolumn{2}{|r|}{ 3. Economic } & 0,45 \\
\hline \multicolumn{2}{|r|}{ Total } & 1,00 \\
\hline \multicolumn{3}{|c|}{ Stage 2 } \\
\hline \multirow[t]{3}{*}{ 1. Political } & 1.1. Terrorist act & 0,05 \\
\hline & 1.2 & 0,10 \\
\hline & $\ldots$ & 0,15 \\
\hline Total Political & & $\mathbf{0 , 2 0}$ \\
\hline \multirow[t]{2}{*}{ 2. Technical } & $\begin{array}{l}\text { 2.1. Lack of necessary modern } \\
\text { equipment }\end{array}$ & 0,18 \\
\hline & 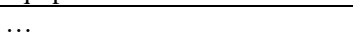 & 0,15 \\
\hline Total Technical & & 0,35 \\
\hline \multirow[t]{2}{*}{ 3. Economic } & 3.1. Inability to get a loan & 0,25 \\
\hline & $\ldots$ & $\ldots$ \\
\hline Total Economic & & 0,45 \\
\hline
\end{tabular}

To provide results in the form presented in Tables 1 and 2 , can be quite inconvenient for each expert because it involves two tasks: not only determining the probability in part of the unit, but also satisfying the condition of obtaining the unit as the sum of all individual scores within one group of problem. Conducting a two-step survey only partially simplifies mathematical operations for experts, although it may distort the results of the assessment in some way, since it is easier to evaluate a particular problem than a group of problems.

Table 3 shows the results of the survey for a predetermined purpose, but the scale is defined from 0 to 10 (single digits are easier to perceive than fractional or multidigit when comparing the criteria). The task for the experts was as follows: to assess the likelihood (frequency) of problems. Similarly, one can evaluate the significance of the 
problems not only in the likelihood but also in the negative effects of the object being evaluated.

TABLE III. EXPERT ASSESSMENT OF PROBABILITY (OPTION 3)

\begin{tabular}{|c|c|c|}
\hline $\begin{array}{c}\text { Group of } \\
\text { problems }\end{array}$ & Partial problem & $\begin{array}{c}\text { Probabil } \\
\text { ity }\end{array}$ \\
\hline \multirow{2}{*}{ 1. Political } & 1.1 . Terrorist act & 2 \\
\cline { 2 - 3 } & 1.2. & 3 \\
\cline { 2 - 3 } & $\ldots$ & 5 \\
\hline \multirow{2}{*}{ 2. Technical } & 2.1. Lack of necessary modern \\
equipment & 4 \\
\cline { 2 - 3 } 3. Economic & $\ldots$ & 10 \\
\cline { 2 - 3 } & 3.1. Inability to get a loan & $\ldots$ \\
\hline
\end{tabular}

After processing the results of the questionnaires in Tables 1 and 2, the researcher immediately receives a probability value. The survey results in Table 3 require simple mathematical transformations, but greatly simplify the evaluation process itself. To obtain the probability of the results of Table 3, it is sufficient for the researcher to divide each individual time estimate by the total amount of estimates.

The rational use of information obtained from experts is possible only if it is transformed into a form that is convenient for further analysis aimed at preparing and making management decisions.

In accordance with the purpose of the study and the models adopted in the analysis of the collected expert data, it is necessary to submit information received from the experts in a form that is convenient for management decision (order objects, indicators, factors, etc.), as well as to determine the coherence of the experts and the reliability of the experts estimates. For example, problems identified in the analysis process should be presented in the order of their importance (probability or degree of impact on the level of losses).

That is, the researcher should develop a questionnaire that is as convenient as possible for the experts and that requires minimal time for the survey itself. With the use of modern information technology, processing procedures do not cause much difficulty, even with a large number of respondents. The researcher can convert the results of the poll on a ten-point scale to any (where the lower bound is 0 and the upper number $\mathrm{T}$ is $1,2,5,100$, etc.) using the following formula:

$$
R_{j}^{\prime}=\frac{R_{j}}{10} \cdot T,
$$

where $R_{j}^{\prime}$ - converted to the $\mathrm{j}^{\text {th }}$ criterion;

$R_{j}$ - baseline score on the $\mathrm{j}^{\text {th }}$ criterion;

$T$ - the upper limit of the scale of the converted scale.

Sometimes there is a need to translate the results of a 10 point scale into a scale whose lower limit is different from 0 , and in this case the researcher can use the following formula:

$$
R_{j}^{\prime}=\frac{R_{j}}{10} \cdot(T-B)+B,
$$

where $B$ - the lower limit of the scale

In Table 4, we look at different options for converting values from a ten-point scale to different variants of study scales.

In addition, after some modification, formula 2 can be used to convert values from any scale to another in the presence of clearly defined upper and lower bounds of the estimate. The modified formula will look like this:

$$
R_{j}^{\prime}=\frac{R_{j}-B_{0}}{\left(T_{0}-B_{0}\right)} \cdot\left(T_{1}-B_{1}\right)+B_{1},
$$

where $T_{0}, B_{0}$ - upper and lower bounds of the baseline score scale;

$T_{1}, B_{1}--$ the upper limit of the scale of the converted scale.

TABLE IV. OPTIONS FOR CONVERTING SCORES ON A 10-POINT SCALE

\begin{tabular}{|c|c|c|c|c|c|c|c|}
\hline $\begin{array}{c}\text { Scores on } \\
\text { a 10-point } \\
\text { scale }\end{array}$ & $0-1$ & $0-2$ & $0-5$ & $1-2$ & $1-5$ & $1-8$ & $10-100$ \\
\cline { 2 - 8 } & 0 & 0 & 0 & 1 & 1 & 1 & 10 \\
\hline 0 & 0,15 & 0,3 & 0,75 & 1,15 & 1,6 & $\begin{array}{c}\text { Scores on Scale } \\
5\end{array}$ & 23,5 \\
\hline 1,5 & 0,2 & 0,4 & 1 & 1,2 & 1,8 & 2,4 & 28 \\
\hline 2 & 0,4 & 0,8 & 2 & 1,4 & 2,6 & 3,8 & 46 \\
\hline 4 & & & & & & 4,8 & \\
\hline 5,5 & 0,55 & 1,1 & 2,75 & 1,55 & 3,2 & 5 & 59,5 \\
\hline 7 & 0,7 & 1,4 & 3,5 & 1,7 & 3,8 & 5,9 & 73 \\
\hline 7,5 & & & & & & 6,2 & \\
& 0,75 & 1,5 & 3,75 & 1,75 & 4 & 5 & 77,5 \\
\hline 8 & 0,8 & 1,6 & 4 & 1,8 & 4,2 & 6,6 & 82 \\
\hline 9 & 0,9 & 1,8 & 4,5 & 1,9 & 4,6 & 7,3 & 91 \\
\hline 10 & 1 & 2 & 5 & 2 & 5 & 8 & 100 \\
\hline
\end{tabular}

The proposed procedure, for example, can be used to translate different assessment scales in higher education institutions. Currently, the following scales are used in educational institutions in Ukraine to evaluate students and students (subject to a positive assessment):

from 3 to 5 ;

from 4 to 12 ;

from 100 to 200 ;

from 3.00 to 5.00 ;

from 60 to 100

The need for transferring different grades arises when transferring to another school or when generating a weighted or average weighted grade when entering higher education institutions. Table 5 provides an example of transferring grades.

This will allow the use of a universal formula for translating estimates without forming individual local calculations in each case and thus providing clarity in the results obtained. 
TABLE V. OPTIONS FOR CONVERTING SCORES

\begin{tabular}{|c|c|c|c|}
\hline \multirow{2}{*}{$\begin{array}{c}\text { Scores on a } \\
\text { scale from } 60 \text { to }\end{array}$} & \multicolumn{3}{|c|}{ Scores on Scale } \\
\cline { 2 - 4 } 100 & $3-5$ & $4-12$ & $100-200$ \\
\hline 60 & 3 & 4 & 100 \\
\hline 62 & 3,1 & 4,4 & 105 \\
\hline 65 & 3,25 & 5 & 112,5 \\
\hline 68 & 3,4 & 5,6 & 120 \\
\hline 70 & 3,5 & 6 & 125 \\
\hline 73 & 3,65 & 6,6 & 132,5 \\
\hline 75 & 3,75 & 7 & 137,5 \\
\hline 78 & 3,9 & 7,6 & 145 \\
\hline 80 & 4 & 8 & 150 \\
\hline 82 & 4,1 & 8,4 & 155 \\
\hline 84 & 4,2 & 8,8 & 160 \\
\hline 85 & 4,25 & 9 & 162,5 \\
\hline 87 & 4,35 & 9,4 & 167,5 \\
\hline 90 & 4,5 & 10 & 175 \\
\hline 92 & 4,6 & 10,4 & 180 \\
\hline 94 & 4,7 & 10,8 & 185 \\
\hline 95 & 4,75 & 11 & 187,5 \\
\hline 97 & 4,85 & 11,4 & 192,5 \\
\hline 99 & 4,95 & 11,8 & 197,5 \\
\hline 100 & 5 & 12 & 200 \\
\hline
\end{tabular}

This fact is confirmed when designing estimates on different scales in the corresponding diagrams (Fig. 1).
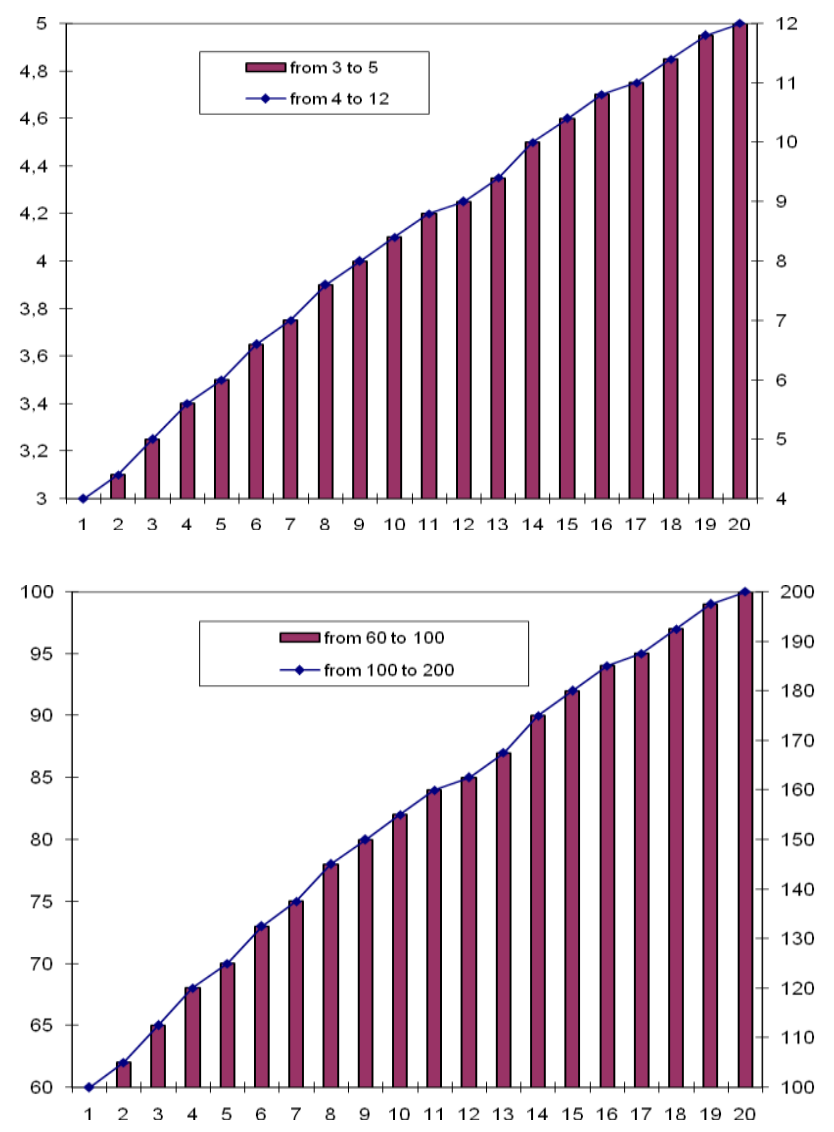

Fig. 1. Visualisation of scores on different scales

Using the type of chart histogram and graph with 2 axes, you can see that the results of the evaluation when converting on different scales are identical.
With regard to expert judgment, the most common methods of ordering are direct evaluation or sequential comparisons (usually used in individual examination), ranking (simple placement from more important to less important, usually by one or more criteria), pairwise comparisons (determining the hierarchy of criterion and constructing pairwise matrices for each pair of scores).

As a rule, individual experts give estimates of the object of study independently, and then these estimates are combined into one final (agreed) using special technique. In order to obtain a final evaluation, the average or weighted average of the estimates is often calculated, and the importance (weight) of both the individual issues (criteria) of the object's assessment and the competence of the experts themselves can be taken into account. These issues are also not always uniquely resolved by researchers and require further clarification of our work.

To assess the consistency of experts, most often use the coefficient of concordance, the magnitude of which allows making a conclusion about the reliability of estimates.

Examples of calculation and criteria for the use of this indicator are widely considered in the literature [2], .[12].

The complexity of the expert evaluation and the lack of information on the evaluation contributed to the emergence of a large number of specialists and specialized firms in Ukraine, publications that offer their forecasts (economic, financial and political nature) to the general public. This is not always done at a sufficiently professional level. It should be noted that any, even unprofessional, assessment (especially if repeated by the media) generates certain expectations in the population and accordingly influences the behaviour of market players. Public institutions should play an important role in streamlining economic expertise. First, the right to systematically publish their estimates should only be given to professionals, specialist firms and publications with sufficient qualifications. Secondly, the expert evaluation must meet certain requirements: its methodology must be clearly defined, quantitative and qualitative and qualitative indicators are justified and so on. In addition, the evaluation should be carried out by either independent rating agencies or official institutions, such as the Chamber of Commerce, the Ukrainian Union of Industrialists and Entrepreneurs, the Union of Small Enterprises of Ukraine, etc.

\section{CONCLUSIONS}

Summarizing the procedure for applying the expert assessment method, we can draw the following conclusions: Thus, we consider this method universally applicable. This allows using it to evaluate any social and economic process or phenomenon. Expert method of estimation of economic phenomena and processes is in one way or another connected with averaging of opinions of specialists that allows eliminate or lessen the problem of subjectivity.

The method allows certain variations in calculations and presentation of the research results. The article suggests a simplified procedure of the scale transformation which can be used by both experienced scientists and non-scientific professionals who use this method at work. 
The method is not always sufficient for scientific research and can be combined with other (quantitative and qualitative) methods to confirm the hypotheses, search, etc. and assure reliability and validity of research. However, it has certain advantages and one of them is that the method works well not only at the stages of evolution of the system (society, enterprise), but also at critical points, where the end of the current trend (clearly defined trend) and the formation of a new one is observed. Although this requires consideration not only of quantitative and qualitative factors, but also of the intuition of experts (subjectivity of the method).

Finally, there are still areas for further research on aggregation of experts' opinions, the use of qualitative and quantitative methods of assessment, and further application of the results in the practice of managing socio-economic systems of different levels.

\section{REFERENCES}

[1] H. A. Linstone, M. Turoff, and O. Helmer, Eds., The Delphi method: Techniques and applications. Addison-Wesley Pub. Co., Advanced Book Program, 2002.

[2] M. K. Rayens and E. J. Hahn, "Building consensus using the policy Delphi method," Policy, Polit. Nurs. Pract., vol. 1, no. 4, pp. 308 $315,2000$.

[3] K. Kauko and P. Palmroos, "The Delphi method in forecasting financial markets - An experimental study," Int. J. Forecast., vol. 30, pp. 313-327, 2014.

[4] V. Modrak and P. Bosun, "Using the Delphi method in forecasting tourism activity," Int. Lett. Soc. Humanist. Sci., vol. 25, pp. 66-72, 2014.

[5] A. J. Fletcher and G. P. Marchildon, "Using the Delphi method for qualitative , participatory action research in health leadership," Int. J. Qual. Methods, vol. 13, pp. 1-18, 2014.

[6] J. Landeta, "Current validity of the Delphi method in social sciences," Technol. Forecast. Soc. Change, vol. 73, no. 5, pp. 467-482, 2006.

[7] C. Hienerth and F. Riar, "The wisdom of the crowd vs. expert evaluation: A conceptualization of evaluation validity," 35th DRUID Celebr. Conf. 2013, pp. 1-31, 2013.

[8] A. Habibi, A. Sarafrazi, and S. Izadyar, "Delphi technique theoretical framework in qualitative research," Int. J. Eng. Sci., vol. 3, no. 4, pp. $8-13,2014$

[9] R. A. Green, "The Delphi technique in educational research," $S A G E$ Open, vol. 4, no. 2, pp. 1-8, Jun. 2014.

[10] I. R. Diamond et al., "Defining consensus: A Systematic review recommends methodologic criteria for reporting of Delphi studies," $J$. Clin. Epidemiol., vol. 67, no. 4, pp. 401-409, 2014.

[11] S. L. Beshelev and F. G. Gurievich, Mathematical and statistical methods of expert evaluation. Moscow: Statistika, 1992 [in Russian].

[12] G. M. Dobrov, Y. M. Yershov, Y. I. Levin, and L. P. Smirnov, Expert estimates in scientific and technical forecasting. Kyiv: Naukova Dumka, 1994 [in Ukrainian]. 